\title{
QUAL DEMOCRACIA: A NECESSIDADE PREMENTE DE ROMPER COM AUNIVOCIDADE IDENTITÁRIA ARTIFICIAL E CASUÍSTICA DO FENÔMENO POLÍTICO
}

WHAT DEMOCRACY: THE PRESSING NEED FOR IDENTITY AUNIVOCIDADE BREAKING WITH ARTIFICIAL AND MATERIAL OF POLITICAL PHENOMENON

Rogério Gesta Leal

RESUMO: O objeto do presente texto é tratar do tema da Democracia a partir de dois referenciais teóricos pontuais: o de Ronald Dworkin e o das Matrizes da Democracia Representativa, Participativa e Deliberativa.

ABSTRACT: The object of this paper is to address the issue of Democracy from two theoretical points: that of Ronald Dworkin and Matrices of Representative, Participatory and Deliberative Democracy.

PALAVRAS-CHAVE: Democracia Representativa - Democracia Participativa Democracia Deliberativa - Ronald Dworkin.

KEY-WORDS: Representative Democracy - Participatory Democracy - Deliberative Democracy - Ronald Dworkin.

\section{INTRODUÇÃO}

Pretendo neste ensaio estabelecer uma reflexão sobre o tema das condições e possibilidades da Democracia contemporânea, envolvendo particularmente as perspectivas política e jurídica trabalhadas por Ronald Dworkin, e verificando em que medida tais elementos se aplicam à realidade brasileira hodierna.

\footnotetext{
${ }^{1}$ Rogério Gesta Leal é Desembargador do Tribunal de Justiça do Estado do Rio Grande do Sul, Doutor em Direito. Prof. Titular da UNISC. Professor da UNOESC. Professor Visitante da Università Túlio Ascarelli - Roma Trè, Universidad de La Coruña - Espanha, e Universidad de Buenos Aires. Professor da Escola Nacional de Formação e Aperfeiçoamento da Magistratura - ENFAM. Membro da Rede de Direitos Fundamentais-REDIR, do Conselho Nacional de Justiça-CNJ, Brasília. Coordenador Científico do Núcleo de Pesquisa Judiciária, da Escola Nacional de Formação e Aperfeiçoamento da Magistratura - ENFAM, Brasília. Membro do Conselho Científico do Observatório da Justiça Brasileira. Coordenador da Rede de Observatórios do Direito à Verdade, Memória e Justiça nas Universidades brasileiras Secretaria de Direitos Humanos da Presidência da República. rleal@unisc.br
} 


\section{A TESE DE RONALD DWORKIN}

Ronald Dworkin, importante filósofo do direito contemporâneo e professor catedrático da Universidade de New York, lançou, em 2006, um texto chamado Is Democracy possible here?, discutindo uma série de questões, dentre as quais, terrorismo e Direitos Humanos, religião e dignidade, impostos e legitimação e, finalmente, o último artigo trata do tema das condições e possibilidades da Democracia em seu país.(DWORKIN, 2006)

Tendo por cenário de fundo as discussões que se davam entre liberais e conservadores envolvendo o governo Bush (filho), e as radicalizações de posturas ideologicamente postas de cada qual, Dworkin chama a atenção para o fato de que os interesses da comunidade estão sendo cada vez mais deixados de lado, até porque, em tais cenários, o interesse de ambos os principais partidos eleitorais nos EUA vem sendo o de: how to win a majority, if only barely, in what was presumed to be a closely split and highly polarized electorate.(STARR, 2010, p.02)

O efeito no eleitorado disto é que ele não sabe diferenciar com nitidez o que distingue a proposta dos partidos e candidatos, uma vez que estão bombardeados por ações de comunicação, propaganda e publicidade voltadas à conquista do voto, independentemente de sua qualidade ou fundamento. É interessante como tais situações vão gerando, por sua vez, a univocidade identitária artificial e casuística do fenômeno político, fragilizando as distinções entre esquerda e direita - por exemplo, e colocando todos os atores da arena política como que compromissados com as mesmas demandas sociais (que também sofrem homogeneização forçada, e passam a ser de todos).

De certa forma este marasmo político foi fator importante na campanha vitoriosa de Barack Obama, na medida em que suas propostas de governo foram construídas sob plataformas distintivas do que até então vinha sendo feito, saindo do status quo vigente que Starr chama de centrismo brando e confuso (bland and muddled centrism). (STARR, 2010, p.02)

Sem sombra de duvidas que Dworkin está certo ao afirmar que o tema dos Direitos Fundamentais hoje - mesmo fora dos EUA - carece de uma preocupação cívica importante, notadamente em face dos poderes instituídos, e mais especialmente no âmbito parlamentar, eis que os legisladores em regra tratam destes pontos com níveis de ambigüidade e falta de decisão muito grande, dizendo: as little as possible 
except in subliminal codes meant secretly to energize important groups. (DWORKIN, 2006, p.129) $)^{2}$

Esquece-se desta forma que a verdade é a melhor referência que se pode ter para tratar disto tudo, todavia, na realidade americana, ela parece estar obsoleta, pelo fato de que: politicians never seek accuracy in describing their own records or their opponents'positions.(DWORKIN, 2006, p.129) Em verdade, o sistema político baseado na lógica do mercado, transforma-se em mais um produto de consumo caro e acessível somente aqueles que têm condições de financiá-lo. Tal financiamento, todavia, representa mais do que acesso, mas controle do sistema político, em outros termos, in politics money is the enemy not just of fairness but of real argument. (DWORKIN, 2006, p.129)

Os níveis de baixaria e agressões nas campanhas políticas contam com apelos midiáticos de espetáculo e diversão, transformando o processo eleitoral em programas de auditório divertidos, como se não tratassem de problemas da vida real (Reason isn't everything, after all, and emotion, of the kind American elections specialize in, has an important place in politics). (DWORKIN, 2006, p.129)

Será que esta fragilidade do sistema parlamentar e representativo não é insuficiente para se pensar as fragilidades da Democracia? Não há outros modelos de participação política (mais direta e presentativa) que possam criar alternativas aos déficits sociais e institucionais da Democracia contemporânea?

Reconhece Dworkin que o critério majoritário da deliberação política não é o único nem o mais importante na experiência Ocidental, eis que, muitas vezes, a vontade das maiorias não garante resultados justos e mais eficientes ao interesse público (que não é só o majoritário), gerando vários níveis de injustiça às minorias - ou mesmo ignorando demandas de minorias (Tese da Democracia Contramajoritária). Quais os níveis de injustiça que uma Democracia suporta?

Daqui surge a idéia de que outro modelo de Democracia pode operar com a idéia de que ela significa o governo de cidadãos que estão envolvidos como grandes parceiros numa empreitada política coletiva, no qual as decisões democráticas só o são na medida em que certas condições estão presentes para os fins de proteger 0 status e os interesses de cada cidadão.

\footnotetext{
${ }^{2} \mathrm{O}$ autor faz menção a eleição de 2004 nos EUA em que foram feitas várias pesquisas para aferir o interesse e o conhecimento do povo americano sobre temas internacionais envolvendo seu pais, e eles nada sabiam disto. Esta lógica de fazer política vai contaminando o processo político como um todo, criando verdadeiros vícios em espiral (vicios spiral winds) de formação e percepção da política,
} afastando a cidadania do seu epicentro.

REVISTA DO DIREITO UNISC, SANTA CRUZ DO SUL No $39 \mid$ p. 03 - 17 |JAN-JUL 2013 
No campo da pragmática e do cotidiano, o que se pode perceber, em regra, é uma total falta de interesse pelos temas políticos e sociais, mesmo os relacionados a direitos civis são objeto de manejo muito mais para o atendimento de interesses privados do que públicos, e na perspectiva majoritária isto se agrava ainda mais, na medida em que as deliberações políticas só levam em conta quem participa e como participam no plano formal do processo político, ou seja, democracy is only about how political opinions are now distributed in the community, not how those opinions came to be formed.(DWORKIN, 2006, p.132)

Dworkin lembra que no modelo da democracia como conjunto de parceiros a perspectiva se diferencia, fundamentalmente porque trabalha com a lógica da mutua atenção e respeito enquanto essência desta matriz, sabendo que igualmente isto não faz parte das tradições e hábitos americanos, principalmente no cotidiano das pessoas e em suas relações com as outras. Registra o autor que: We do not treat someone with whom we disagree as a partner - we treat him as an enemy or at best as an obstacle when we make no effort either to understand the force of his contrary views or to develop our own opinions in a way that makes them responsive to his. (DWORKIN, 2006, p.132)

Claro que em tempos de guerra e desconfianças mutuas as possibilidades de tratamento do outro com respeito se afiguram escassas, o que não justifica a paralisia diante de situações que reclamam mudança estrutural e funcional, sob pena de comprometimento não somente das relações intersubjetivas, mas das próprias relações institucionais em face da Sociedade.

Em verdade, e é o próprio autor que diz isto, a concepção majoritária de democracia não leva em conta outras dimensões da moralidade política - resultando dai que uma decisão pode ser democrática sem ser justa -, enquanto que na perspectiva da democracia entre parceiros estão presentes outras considerações que meramente as processuais/formais, reclamando uma verdadeira teory of equal partnership, na qual se precisa consultar questões como justiça, igualdade e liberdade de todos os envolvidos. So on the parthership conception, democracy is a substantive, not a merely procedural ideal. (DWORKIN, 2006, p.129) ${ }^{3}$

Dai que também não resolve ter-se um super-ativismo por parte da sociedade civil na direção de propugnar por uma democracia que venha a produzir decisões

\footnotetext{
${ }^{3}$ Ver o texto de ESKRIDGE, Paul Public values in statutory interpretation. In University of Pennsylvania Law Review. [s.l.]: [s.n.], [1989]. v. 137.

REVISTA DO DIREITO UNISC, SANTA CRUZ DO SUL No $39 \mid$ p. 03 - 17 | JAN-JUL 2013
} 
políticas substanciais de preferências seletivas majoritárias, porque novamente interesses contra-majoritarios podem ser violados de forma antidemocrática.

Em face também disto é que Dworkin identifica a migração da batalha sobre a natureza da democracia e sua operacionalidade à Suprema Corte, outorgando-se a si própria legitimidade para declarar atos de competência originária de outros poderes, isto em nome, fundamentalmente, de que a Constituição Americana limita os poderes das políticas majoritárias ao reconhecer direitos individuais - e de minorias - que não podem ser violados. Um pouco é nesta direção a critica no sentido de que os juízes estariam inventando novos direitos e colocando-os dentro da Constituição como forma de substituir as instituições representativas e democráticas por seus valores pessoais ou de quem representam. ${ }^{4}$

Num caso específico envolvendo um jovem hospitalizado em estado terminal na Flórida, e vivendo somente com aparelhos, como conta Dworkin, sua família autorizou, com permissão judicial, o desligamento destes aparelhos porque isto evitaria maior sofrimento e a sua situação clínica e orgânica era irrecuperável. Imediatamente a reação do Congresso na sua maioria republicana foi feroz contra a decisão judicial, chegando inclusive a criar norma específica no sentido de que isto não poderia ocorrer até a decisão transitar em julgado. Alguns republicanos chegaram a prestar declarações ofensivas ao Poder Judiciário, dizendo estar ocorrendo verdadeira insubordinação em face do que o Parlamento decidira, pois: Once Congress had made its will known, it was the duty of judges to execute that will because Congress is elected by and represents the majority of the people. (DWORKIN, 2006, p.136) ${ }^{5}$

O problema é que esta discussão está entrincheirada ainda em pequenos círculos de poder e de instituições já organizadas no mercado e nas relações sociais, não se podendo extrair daqui - ao menos para o Brasil e mesmo para os EUA reflexos na opinião pública geral; ao contrário, pela reflexão de Dworkin, com o que concordo no ponto, a opinião pública sobre a natureza da democracia (que é o que está envolvido nesta discussão) depende muito mais do que os sujeitos que a

\footnotetext{
${ }^{4}$ In recent decades the main battles about the nature of democracy have been fought over judges and over the Supreme Court's authority to declare acts of other branches of government unconstitutional. The American Constitution limits the power of political majorities by recognizing individual constitutional rights that majorities may not infringe. (DWORKIN, 2006, p.135). Ver também o texto DWORKIN, Ronald. The Moral Reading of the Constitution. In http://www.nybooks.com/articles, VOLUME 43, NR.5, MARCH, 21, 1996.

${ }^{5}$ Dworkin adverte que: Liberals were in turn outraged by the Republican reaction; they said that Republicans were rejecting the independence of the judiciary and the rule of law. Disagreement about the nature of democracy shone through this confrontation.
}

REVISTA DO DIREITO UNISC, SANTA CRUZ DO SUL No $39 \mid$ p. 03 - 17 |JAN-JUL 2013 
representam acreditam serem os melhores meios e formas de conseguirem seus objetivos, sem envolver necessariamente preocupações com os impactos e efeitos que isto pode acarretar ao interesse público da comunidade. ${ }^{6}$

Desta forma, a regra majoritária de deliberação política - divorciada de uma opinião pública qualificada por seus argumentos - não assegura maiores níveis de legitimação do que deliberações monocráticas decorrentes de processos de consulta ou discussão pública efetiva. Falha inclusive aqui o chamado Teorema de Condorcet, para o qual a soma quantitativa majoritária das escolhas individuais homogêneas maximiza a chance de que se chegará a resultados democráticos e satisfativos, pois se teria de perguntar: satisfativo para quem? No mínimo - e nem isto está garantido - para aquela parte quantitativa de indivíduos que tiveram articulação e mobilidade política eficaz para o fim almejado.(DWORKIN, 2006, p.140)

Mesmo a perspectiva de que a regra das escolhas e deliberações majoritárias venham a estabelecer vínculos políticos e institucionais (com parlamentares e partidos), independentemente da forma constitutiva das escolhas/deliberações, não garante tratamento isonômico às escolhas e pretensões contra-majoritárias. Como lembra Dworkin, os temas que envolvem políticas públicas apresentam não raro fundamentos morais de alta complexidade, not strategies about how to please most people.(DWORKIN, 2006, p.141)

Por outro lado, o autor americano toca em ponto nodal desta discussão que diz com os déficits democráticos efetivos do modelo da democracia representativa - ao menos historicamente -, na medida em que ela opera com o pressuposto equivocado de que há equilíbrios perenes nas bases da representação que a institui:

Political Power also very much differs because some of us are much richer than others, or more persuasive in discussion, or have more friends or a larger family, or live in states where the two great political parties are more evenly divided than where others live so that our votes are marginally more likely to make a real difference. These are all familiar reasons why the idea of equal political power is a myth. (DWORKIN, 2006, p.142)

E sem sobras de dúvidas trata-se de um mito este equilíbrio/igualdade política dos poderes públicos instituídos - quiçá uma idéia regulativa, a ser permanentemente buscada como forma de compromisso com tal modelo de Democracia. Isto é tão claro que hoje, no Brasil, uma discussão acadêmica e política importantíssima é a do

\footnotetext{
${ }^{6}$ Ou seja, people's opinion about the nature of democracy are likely to be driven by what they believe to be the best means of realizing their other political goals. (DWORKIN, 2006, p.138)

REVISTA DO DIREITO UNISC, SANTA CRUZ DO SUL No $39 \mid$ p. 03 - 17 | JAN-JUL 2013
} 
chamado ativismo judicial em face do Legislativo e do Executivo, a ponto de matérias jornalísticas darem conta de que:

Congresso reage a atos do Judiciário. Parlamentares estão descontentes com o que dizem ser interferência do STF.

Insatisfeito com o resultado de julgamentos de temas políticos e desconfiado com as últimas propostas do Supremo Tribunal Federal (STF), o Congresso reagiu, na tentativa de conter a atuação do Judiciário. $\mathrm{O}$ deputado petista Nazareno Fonteles, do PI, propôs uma mudança na Constituição que daria ao Congresso poder para sustar atos normativos do poder Judiciário.

Além da nova proposta, deputados tiram das gavetas projetos que podem constranger o Judiciário. As mais recentes decisões do STF - de alterar a aplicação da Lei da Ficha Limpa e de definir qual suplente de deputado a Câmara deve dar posse - reacenderam a animosidade entre os dois poderes. A irritação aumentou com a proposta do presidente do STF, Cezar Peluso, de instituir um controle prévio de constitucionalidade das leis.

As reações do Congresso, do governo e do próprio STF fizeram Peluso recuar. Mas o atrito já estava formado. "Aos poucos, estão criando uma ditadura judiciária no país", disse Fonteles.

Em uma semana, o deputado recolheu quase 200 assinaturas e apresentou uma proposta de emenda constitucional para permitir ao Legislativo "sustar atos normativos dos outros poderes que exorbitem do poder regulamentar ou dos limites de delegação legislativa". Atualmente, esse artigo (art. 49) permite a suspensão pelo Congresso de atos do Executivo. A alteração estende a permissão ao Judiciário. "Não podemos deixar o Supremo, com o seu ativismo, entrar na soberania popular exercida pelo Congresso. O Supremo está violando a cláusula de separação dos poderes, invadindo competência do Legislativo", argumentou Fonteles.

A chamada judicialização da política e a concentração de poderes nas mãos dos onze ministros do STF levaram o ex-juiz federal e ex-deputado Flávio Dino (PC do B-MA) a apresentar uma proposta de emenda constitucional acabando com o cargo vitalício dos ministros do Supremo. O projeto, de 2009, ainda está à espera de apreciação por parte da Comissão de Constituição e Justiça da Câmara. Para Dino, a determinação do STF de aplicar a Ficha Limpa nas próximas eleições e as decisões sobre qual suplente deve dar posse no caso de afastamento do deputado titular reforçam a necessidade de evitar a submissão da política a uma aristocracia judiciária. - Na prática, o Supremo decidiu o resultado das eleições, substituindo a soberania popular - resume Dino.

Enquanto as propostas de emenda constitucional não entram na pauta, Fonteles conseguiu aprovar a realização de um seminário na Comissão de Constituição e Justiça da Câmara para discutir a relação entre o Legislativo e o Judiciário. $\mathrm{O}$ evento está marcado para a próxima terça-feira. ${ }^{\top}$

Afigura-se como muito perigoso o tratamento desta questão nos termos apresentados pelo informe jornalístico, a despeito de que faça parte da estratégia político-parlamentar tensionar com a opinião pública determinados assuntos para ver como ela reage antes da tomada de medidas mais efetivas.

\footnotetext{
7 Jornal Correio do Povo, edição do dia 25/04/2011, Política - página 4, Porto Alegre, Rio Grande do Sul, Brasil. Tratei de forma mais aprofundada deste tema no texto LEAL, Rogério Gesta. As responsabilidades políticas do Ativismo Judicial: aspectos teórico-práticos da experiência norteamericana e brasileira. In LEAL, Rogério Gesta § LEAL, Mônia Clarissa Hennig. Ativismo Judicial e Déficits Democráticos: algumas experiências latino-americanas e européias. Rio de Janeiro: Lúmen Júris, 2011.

REVISTA DO DIREITO UNISC, SANTA CRUZ DO SUL No $39 \mid$ p. 03 - 17 | JAN-JUL 2013
} 
Em verdade, considerando ser a Democracia contemporânea uma tentativa de dar efetividade à idéia de self-government, na qual a soberania popular governa a si própria através de mecanismos de presentação e representação, é a inter-relação entre todos estes mecanismos, com o que Dworkin chama de equal concern, que deve pautar as interlocuções, deliberações e as políticas públicas de governo, isto fundado na premissa de que, though it would compromise my dignity to submit myself to the authority of others when I play no part in the their decisions, my dignity is not compromised when I do take part, as an equal partner, in those decisions. (DWORKIN, 2006, p.144). Daí a importância contra-majoritária do exercício do Poder.

Outro ponto polêmico nesta discussão - e bem abordado por Dworkin - diz com a compatibilidade, ou não, da existência de direitos individuais que não possam ser submetidos à vontade das maiorias, tal como a religião, por exemplo, isto porque uma compreensão mais cidadã da ordem constitucional republicana e democrática impõe o que o autor americano chama de partnership conception, a qual requires some guarantee that the majority will not impose its will in these matters. (DWORKIN, 2006, p.146) $)^{8}$

A Procuradoria Geral da República no Brasil ajuizou ação direta de inconstitucionalidade junto ao Supremo Tribunal Federal para restringir o ensino religioso nas escolas públicas, limitando os termos do acordo do país com o Vaticano nesta questão. ${ }^{9} \mathrm{O}$ argumento do Ministério Público se centrou na impossibilidade de que os órgãos públicos se vinculem a qualquer religião, estabelecendo algum tipo de exclusividade ou preferência, em face exatamente da laicidade do Estado Democrático de Direito contemporâneo.

Assim, a separação entre Estado e Igreja contempla não apenas a proibição de uma religião oficial (como era a católica anteriormente), como estabelece a liberdade religiosa e a proteção a todo e qualquer culto, a despeito da Constituição nacional prever a existência do ensino religioso, de caráter facultativo, nas escolas públicas.

${ }^{8}$ Diz ainda o autor: On the partnership conception, therefore, constitutional rights protecting an individual's freedom to make ethical choices for himself are not compromises of democracy but rather attempts to guarantee it.

${ }_{9}$ In http://terramagazine.terra.com.br/interna/0,,Ol4640796-El16410,00Acao+no+STF+quer+limitar+ensino+religioso.html, acessado em 20/10/2011. Ainda refere a matéria jornalística que o julgamento da ação deveria ser precedido, se atendido o pedido da Procuradoria Geral da República, de audiência pública, o que permitiria que várias linhas de pensamento, inclusive e principalmente as religiosas (como também aconteceu no julgamento da utilização de células troncoembrionárias), se expressem. 
A polêmica suscitada na argüição da Procuradoria diz respeito ao texto do acordo do Brasil com o Vaticano sobre esta matéria, um dos temas que provocou a visita do papa Bento XVI ao Brasil em 2007, eis que esta avença, dentre outras coisas, estabelece o estatuto da Igreja Católica no país, seus direitos e, principalmente, suas imunidades, dispondo que o ensino religioso nas escolas públicas será católico e de outras confissões religiosas.

A Procuradoria propõe que o STF entenda que o ensino da religião deva ser não-confessional, tratado como história das religiões e ministrado por professores leigos - nem católicos, nem de outras igrejas. Por tal tese, o conteúdo da disciplina consistiria apenas na exposição de doutrinas, das práticas, da história e de dimensões sociais das diferentes religiões, assim como das posições não religiosas ou atéias. ${ }^{10}$

Mais recentemente e ainda envolvendo o tema da religião, o Poder Judiciário do Estado do Rio Grande do Sul, por seu Conselho de Administração, tratou da exposição de crucifixos nos espaços públicos dos prédios do Poder Judiciário gaúcho, concluindo que a presença de crucifixos e demais símbolos religiosos nos espaços do Poder Judiciário destinados ao público não se coaduna com o princípio constitucional da impessoalidade na Administração Pública e com a laicidade do Estado brasileiro. ${ }^{11}$

Outro exemplo disto pode ser visualizado no caso conhecido como Marcha da Maconha, no qual o Supremo Tribunal Federal sustentou a legalidade do evento que reúne manifestantes favoráveis à descriminalização da droga (isto ocorreu em 23/11/2011, autos da ADI no 4274). Por unanimidade, os ministros decidiram que esse tipo de manifestação não pode ser considerado crime previsto no artigo 33, parágrafo $2^{\circ}$, da Lei de Tóxicos (Lei $n^{\circ}$ 11.343/2006), o que configuraria afronta aos direitos de reunião e de livre expressão do pensamento, previstos na Constituição Federal.

O Plenário seguiu o voto do ministro Ayres Britto, relator da Ação Direta de Inconstitucionalidade, proposta pela Procuradoria-Geral da República (PGR), determinando que o dispositivo da Lei de Tóxicos - que classifica como crime o ato de induzir, instigar ou auxiliar alguém ao uso indevido de droga - seja interpretado em conformidade com a Constituição Federal, excluindo-se daí a interpretação da norma qualquer significado que enseje a proibição de manifestação e debates públicos acerca

10 Conforme notícia veiculada no http://terramagazine.terra.com.br/interna/0,,Ol4640796-El16410,00Acao+no+STF+quer+limitar+ensino+religioso.html, acessado em 04/05/2011.

${ }_{11}$ Autos do processo $\mathrm{n}^{\circ} 0139-11 / 000348-0$, tendo como partes provocadoras do expediente administrativo referido as seguintes instituições: Rede Feminista de Saúde, SOMOS - comunicação, saúde e sexualidade; NUANCES - grupo pela livre orientação sexual; Liga Brasileira de Lésbicas; Marcha Mundial de Mulheres; THEMIS - assessoria jurídica e estudos de gênero, tendo como Relator Des. Claudio Baldino Maciel, decidido em 06/03/2012.

REVISTA DO DIREITO UNISC, SANTA CRUZ DO SUL No $39 \mid$ p. 03 - 17 | JAN-JUL 2013 
da descriminalização ou legalização de drogas ou de qualquer substância que leve ao entorpecimento episódico ou viciado das faculdades psicofísicas.

Segundo o ministro Ayres Britto, o direito de reunião, assim como os direitos à informação e à liberdade de expressão, fazem parte do rol de direitos individuais de matriz constitucional, tidos como direta emanação do princípio da dignidade da pessoa humana e da cidadania.

De acordo com o relator, existe na Constituição apenas uma única vedação ao direito de reunião, referente àquelas cuja inspiração ou o propósito da convocação ensejem a prática violência física armada ou beligerante. Quem quer que seja pode se reunir para o que quer que seja, no plano dos direitos fundamentais, desde que o faça de forma pacífica, concluiu o ministro Ayres Britto, acrescentando que não se pode confundir a criminalização da conduta (o uso de drogas), com o debate sobre a referida criminalização, que é o propósito da marcha da maconha.

É preciso reconhecer, por outra via, que com a decisão, o STF reforçou o posicionamento firmado em junho deste ano, no julgamento da ADPF $\mathrm{n}$ ํ187, da relatoria do ministro Celso de Mello, quando a Suprema Corte liberou a realização da marcha da maconha por entender que o artigo 287, do Código Penal, deve ser interpretado conforme a Constituição, de forma a não impedir manifestações públicas em defesa da legalização de drogas. Defendeu o Ministro Celso de Mello que:

\begin{abstract}
A mera expressão de pensamento não pode ser objeto de restrição, sob pena de se estabelecer um domínio institucional sobre o pensamento crítico. A defesa, em espaços públicos, da legalização das drogas, longe de significar um ilícito penal, quer sob a égide do Código Penal, quer sob o disposto na Lei de Tóxicos - supostamente caracterizador de apologia ou instigação ao uso de drogas ilícitas -, representa, na verdade, a prática legítima do direito à livre manifestação do pensamento, propiciada pelo direito de exercício de reunião.
\end{abstract}

Por outro lado, ao votar neste caso, o ministro Gilmar Mendes, de forma absolutamente acertada, salientou a importância de esclarecer para a sociedade os limites da decisão do STF, que se refere à legalidade de eventos públicos favoráveis à descriminalização da droga. O Ministro alertou que a decisão da Suprema Corte não pode ser entendida de maneira generalizada, aplicável a toda espécie de reunião que discuta temas diversos do tratado na referida ação, como reuniões favoráveis à descriminalização de outros atos, como racismo ou aborto, por exemplo, evidenciando que a quebra de determinados tabus sociais não compete prioritariamente ao Poder Judiciário, sob pena de excesso de intervenção jurisdicional em temas que são de 
responsabilidade da Sociedade Civil resolver através de suas representações populares e institucionais. $^{12}$

Aqui entra outro debate conexo ao que estou enfrentando que é exatamente o da satisfatividade e eficácia das matrizes democráticas que se tem adotado historicamente (representativa e participativa), ou se é possível e recomendado que se pense em alternativas, como a democracia deliberativa, por exemplo.

\section{A DEMOCRACIA DELIBERATIVA COMO COMPLEMENTO DA REPRESENTAÇÃO POLÍTICA}

Já tive oportunidade de tratar deste tema em obra específica ${ }^{13}$ e, desde lá, tenho sustentado que o modelo da Democracia Representativa que se fortifica na Idade Moderna - com suas instâncias estatais e político-partidárias - foi progressivamente esgotando sua força legítima exclusiva de veicular todas as demandas sociais à esfera das políticas públicas satisfativas.

Em face disto é que começam a surgir de modo mais específico, a partir da década de 1960, movimentos sociais autônomos e orgânicos que reclamam o envolvimento nos processos decisionais de sujeitos e grupos até então excluídos da gestão pública cotidiana. Todavia, la richiesta di maggiore partecipazione era però interamente contenuta - questo è il tratto caratteristico rispetto ad oggi- all'interno dei circuiti della amministrazione pubblica. (RÖCKE, 2006, p 21)

Nesta experiência, os papéis dos partidos políticos como instâncias de representação privilegiados, porque efetivamente preocupados com os interesses públicos que deveriam gerir em face do Poder Executivo, garantiam níveis de coerência e resultados à população questionados - como se viu na crítica de Dworkin. Aliás, como lembra Bobbio, desde este época, nella specificità della situazione italiana, la richiesta si traduceva in una maggiore partecipazione e coinvolgimento del principale partito di opposizione alle decisioni pubbliche, nel presupposto della sua alta rappresentatività nei confronti dei soggetti deboli ed esclusi. (BOBBIO, 2006, p. 40)

\footnotetext{
${ }^{12} \mathrm{Na}$ mesma direção andou o Ministro Cezar Peluso, ao sustentar que não é possível traçar todos os limites de forma abstrata, sendo necessário que a Corte analise caso por caso, quando assim for necessário. Devemos examinar se a questão discutida em cada caso não vai resultar em uma outorga de legitimidade a certos atos que repugnariam à consciência democrática, coletiva e ao próprio sistema jurídico constitucional de um país civilizado.

${ }^{13}$ Estou falando do livro LEAL, Rogério Gesta (organizador). A Democracia Deliberativa como matriz de gestão pública: alguns estudos de casos. Santa Cruz do Sul: Edunisc, 2011, somente no formato Ebook, acesso gratuito em www.unisc.br/edunisc.
}

REVISTA DO DIREITO UNISC, SANTA CRUZ DO SUL No $39 \mid$ p. 03 - 17 |JAN-JUL 2013 
Em face disto é que a Democracia Participativa ganha espaço e se desenvolve já como contraponto da Democracia Representativa exatamente em face do esgotamento de suas possibilidades institucionais e políticas. O problema é que também há déficits na matriz participativa no que diz com a forma, quantidade e qualidade da participação, haja vista os níveis de cooptação ideológica, burocrática e econômica dos atores participantes em relação a interesses mais privados do que públicos.

Daí o surgimento da matriz da Democracia Deliberativa, que começa a ser mais bem teorizada a partir da década de 1980, com pressupostos epistêmicos e metodológicos diferenciados, reconhecendo Luigi Bobbio que mentre la Democrazia Partecipativa ci arriva dalle concrete esperienze del Sudamerica, la Deliberativa proviene dall'ambiente culturale anglosassone. (BOBBIO, 2006, p. 40)

Em verdade, como quer Follesdal, tanto a Democracia Participativa como a Deliberativa se colocam no mesmo campo teórico, pois se ocupam de igual problema, a saber, como instituir e dar efetividade à participação social e à abertura dos processos decisionais públicos nos mais diversos níveis de governo a todos os interessados, destacando que o conceito deliberativo remete a complexos conjuntos teóricos, com conotações fortemente normativas, enquanto que a participação implica aspectos sobretudos aplicativos. (FOLLESDAL, 2006, p.57) ${ }^{14}$

Interessante a lembrança de Paolo Ginsborg:

\begin{abstract}
Sarà forse per la diversa cultura di provenienza, sarà per le successive sovrapposizioni concettuali dovute alle reciproche influenze culturali, è vero che non è del tutto chiaro se tra democrazia deliberativa e democrazia partecipativa - termini che discendono dalla diffusa terminologia anglosassone: deliberative democracy, participative democracy, participatory democracy - esistano differenze teoriche e/o applicative o esprimano identiche esigenze. (GINSBORG, 2006, p.105) ${ }^{15}$
\end{abstract}

Discordando do autor referido, tenho que o acento diferenciador da matriz deliberativa é justamente o processo decisional que decorre dela - matéria estranha à reflexão de Dworkin, fruto da troca de informações e de argumentos qualificados entre

\footnotetext{
${ }^{14}$ Pergunta ainda o autor: What constitutes a deliberation, a subject of intensive consideration among political theorists? One key constituent of deliberation, agreed upon by many theorists, is equality or fairness. All participants and stakeholders should in principle have an equal chance to affect the topic, contents, and outcomes of the deliberation.

${ }^{15}$ Refere ainda o autor que: $A$ tal fine mi pare che la maggioranza degli studiosi siano concordi nell'individuare i due seguenti elementi distintivi: 1) tutte le forme di democrazia partecipativa danno vita a tecniche dirette a permettere che tutti coloro che sono interessati da una decisione pubblica siano consultati ed esprimano una propria posizione; 2) l'effetto della partecipazione non è quello di trasferire il potere decisionale finale in capo ai partecipanti.
}

REVISTA DO DIREITO UNISC, SANTA CRUZ DO SUL No $39 \mid$ p. 03 - 17 | JAN-JUL 2013 
os sujeitos políticos conscientes e envolvidos; assim, diferentemente dos processos decisionais operados sob o mecanismo do voto formal ou da negociação pautada por regras de mercado tão somente - padrão funcional da Democracia Representativa e mesmo Participativa -, a Democracia Deliberativa demanda, para ser legítima, consensos racionais dentre os que são potencialmente interessados no objeto da deliberação capazes de gerar entendimentos sustentáveis. ${ }^{16}$

Em outras palavras, se a Democracia Representativa se afigura como modelo de gestão pública que institucionaliza mecanismos de repartição de competências e funções entre Estado e Sociedade Civil (Poder Executivo, Poder Legislativo - sufrágio, Partidos Políticos, Processo Legislativo, etc. -, e Poder Judiciário); e a Democracia Participativa amplia ainda mais estes espaços institucionais de relações (Conselhos Federais, Estaduais e Municipais de Gestão Pública, Parcerias Público-Privadas, Ações de Voluntariado, etc.); a Democracia Deliberativa se ocupa, para além disto, dos elementos procedimentais e principiológicos que viabilizam materialmente tais relações, radicalizando o envolvimento Social em todas as instâncias de constituição do espaço público, pré e pós-decisionais. ${ }^{17}$

E não se diga que há dificuldades materiais de viabilização da participação crítica e consciente de todos no processo decisional, isto porque, a uma, tem-se hoje ferramentas virtuais e de comunicação eficientes para vencer barreiras físicas e temporais; a duas, porque pende para o Estado a responsabilidade maior de encontrar meios à efetivação do compartilhamento da gestão, em face até de sua melhor estrutura para tanto.

Em face destes elementos não posso aceitar o argumento de Dworkin para justificar o que sejam Direitos e Valores Fundamentais de uma Sociedade Democrática, ancorados em dois princípios sobre a dignidade humana na Filosofia Ocidental contemporânea: (a) o do intrínseco valor da dignidade humana, no sentido de que quando a vida inicia, o que importa objetivamente é que ela se desenvolva com dignidade em todas as suas potencialidades; (b) e o da responsabilidade pessoal, no

\footnotetext{
${ }^{16}$ Ver os textos de ALEEN, Anita $\S$ REGAN, Milton C. Debating Democracy's Discontent. Essays on American Politics, Law and Public Philosophie. Oxford: Oxford University Press, 1998, e BARBER, Benjamin R. Strong Democracy: Participatory Politics for a New Age. Berkeley: University of California Press, 2002.

${ }^{17}$ Ou como quer Ferdinand Robbe, par la démocratie partecipative, le citoyen est invité à s'impliquer non seulement dans la préparation e l'adoption de la norme, mais également dans son application voire dans l'évaluation de son efficacité pratique...ll s'agit en quelque sorte d'une démocratie post-decisionnelle.
} (ROBBE, 2007, p.41) 
sentido de que cada um tem responsabilidades no que toca ao bem estar e desenvolvimento da vida em comunidade. ${ }^{18}$

É como se para o autor norte-americano o universo de variáveis que cercam a condição de ser no mundo em nada afetassem as escolhas e decisões, assim como as ações baseadas nestas escolhas, tomadas diuturnamente.

A partir destas perspectivas, fica fácil para o autor reivindicar que as comunidades políticas têm várias artificialidades e pouca organicidade, afigurando-se mais como coleções de indivíduos (collection of individuals) (DWORKIN, 2011, p.327 $)^{19}$, na qual somente alguns têm papéis/funções específicas, bem como detém poderes que os permitem agir, individual ou conjuntamente - enquanto justaposição de interesses e não orgânicamente em face do interesse público -, representando artificiosamente a comunidade como um todo.

Se esta é a realidade das coisas e das relações sociais, por certo que assim não deveria ser, mas Dworkin não está preocupado em trabalhar com conceitos, idéias e perspectivas regulativas - centradas também na lógica do dever ser-, levando seu pragmatismo individualista ao extremo para sustentar que aquela responsabilidade individual deve conduzir as pessoas ao caminho do bem dos seus semelhantes enquanto indivíduos, resultando daí um somatório positivo e moralmente sustentável. ${ }^{20}$

Lêdo engano, principalmente por crer que a base de sustentação da justiça e equidade social seja a liberdade, quando na verdade é a igualdade (formal e material), pois sem esta afigura-se difícil o desenvolvimento das condições objetivas e subjetivas à emancipação social e participação política.

\section{REFERÊNCIAS}

\footnotetext{
${ }^{18}$ Nas palavras do autor: each of us has special responsibility for making a success of our lives; we are responsible for finding value in life and deciding what kind of life to lead. (DWORKIN, 2011, p.100)

${ }^{19}$ Aqui especificamente o autor faz menção ao fato de estar confirmando suas teses e opiniões de trabalhos mais antigos, como o texto Is Democracy possible here? Principles for a New Political Debate. Op.cit.. Ver o excelente texto de ALLAN, James. The Supreme Court Phalanx: an Exchange. In The New York Books Revew, V.54, № 19, 06/12/2007, P.02, quando lembra que: But Dworkin has long maintained that these principles underlie his own egalitarian liberalism; at the beginning of his 2000 book Sovereign Virtue, which incorporates more than two decades of his work on the moral foundations of politics, he presents the two principles in almost identical language.

${ }^{20}$ Quase como uma concessão, Dworkin.
}

REVISTA DO DIREITO UNISC, SANTA CRUZ DO SUL No $39 \mid$ p. 03 - 17 | JAN-JUL 2013 
ALEEN, Anita § REGAN, Milton C. Debating Democracy's Discontent. Essays on American Politics, Law and Public Philosophie. Oxford: Oxford University Press, 1998.

ALLAN, James. The Supreme Court Phalanx: an Exchange. In The New York Books Revew, V.54, № 19, 06/12/2007.

BARBER, Benjamin R. Strong Democracy: Participatory Politics for a New Age. Berkeley: University of California Press, 2002.

BOBBIO, Luigi. Dilemmi della Democrazia Partecipativa. In Democrazia e Diritto. Vol.4. Roma: Einaudi, 2006.

DWORKIN, Ronald. Is Democracy possible here? Principles for a New Political Debate. Princeton: Princeton University Press, 2006.

----. Justice for Hedgehogs. New York: Harvard University Press, 2011.

DWORKIN, Ronald. The Moral Reading of the Constitution. In http://www.nybooks.com/articles, VOLUME 43, NR.5, MARCH, 21, 1996.

ESKRIDGE, Paul Public values in statutory interpretation. In University of Pennsylvania Law Review. [s.I.]: [s.n.], [1989]. v. 137.

FOLLESDAL, Anthony. The Value Added by Theories of Deliberative Democracy. Where (not) to Look. In: BOSSON, S.; MARTÍ, J. L. (Eds.) Deliberative Democracy and its Discontents. Aldershot: Ashgate, 2006.

GINSBORG, Paolo. La democrazia che non c'è. Torino, Einaudi, 2006.

LEAL, Rogério Gesta (organizador). A Democracia Deliberativa como matriz de gestão pública: alguns estudos de casos. Santa Cruz do Sul: Edunisc, 2011, somente no formato E-book, acesso gratuito em www.unisc.br/edunisc.

----. As responsabilidades políticas do Ativismo Judicial: aspectos teórico-práticos da experiência norte-americana e brasileira. In LEAL, Rogério Gesta § LEAL, Mônia Clarissa Hennig. Ativismo Judicial e Déficits Democráticos: algumas experiências latino-americanas e européias. Rio de Janeiro: Lúmen Júris, 2011.

ROBBE, Ferdinand. Démocratie représentative et participation. Paris: L'Harmattan, 2007.

RÖCKE, Arturo; SINTOMER, Yves. Estrazione a sorte e democrazia partecipativa: riflessioni sugli esiti delle giurie civiche berlinesi. In Democrazia e Diritto. Vol. 3. Roma: Einaudi, 2006.

STARR, Paul. Liberalism for Now. In www.nybooks.com/articles, Volume 56, №12, julho de 2009, acessado em 10/02/2010.

Recebido para publicação: 07/04/2012

Aceito para publicação: 24/04/2013 